OPEN ACCESS

Edited by:

Jesus de la Fuente

University of Navarra, Spain

Reviewed by:

Norzarina Mohd-Zaharim University of Science, Malaysia, Malaysia

Travis G. Gerwing,

LGL Ltd, Canada

*Correspondence:

Jerrell C. Cassady

jccassady@bsu.edu

Specialty section:

This article was submitted to

Educational Psychology,

a section of the journal

Frontiers in Education

Received: 31 August 2018 Accepted: 01 February 2019

Published: 22 February 2019

Citation:

Cassady JC, Pierson EE and Starling JM (2019) Predicting Student Depression With Measures of General and Academic Anxieties. Front. Educ. 4:11. doi: 10.3389/feduc.2019.00011

\section{Predicting Student Depression With Measures of General and Academic Anxieties}

\author{
Jerrell C. Cassady ${ }^{1 *}$, Eric E. Pierson ${ }^{1}$ and J. Michael Starling ${ }^{2}$ \\ ${ }^{1}$ Department of Educational Psychology, Ball State University, Muncie, IN, United States, ${ }^{2}$ Department of Psychology, \\ University of Wisconsin-Stout, Menomonie, WI, United States
}

Universities are increasingly cognizant of the importance of attending to the psychological and emotional needs of undergraduate learners, recognizing that anxiety and depression have significant negative impacts on student retention and success. The focus of the current study was to evaluate the connections among various forms of anxiety and examine the relationships these indicators of anxiety have with depression. The results demonstrated that a broad measure of neuroticism was a meaningful predictor for depression. However, precision in detecting depressive symptoms was improved when examining an additional measure specifically focused on academic anxiety. The results provide support for a nested model of anxiety, which suggests that broad neuroticism, then academic anxiety, and finally test anxiety are progressively more specific manifestations of anxiety in university students. The collection of these findings provide early indication of avenues that may support learners who are beginning to exhibit signs of emotional distress, potentially reducing the tendency to progress from a contextual anxiety response to more serious mental health concerns.

Keywords: anxiety, depression, academic anxiety, university students, big five - personality

\section{ANXIETY AND DEPRESSIVE DISORDERS}

The prevalence rate for a Major Depressive Disorder (MDD) in the United States is estimated at $7 \%$, with most individuals experiencing the first episode of MDD by their mid $20 \mathrm{~s}$ (American Psychiatric Association, 2000). However, the estimated rate of symptomatic expression of depression for those who do not meet criteria for a MDD is much higher-particularly in college samples (Keyes, 2006). Examination of a national sample of clinics on college and university campuses confirmed that among over 53,000 students, anxiety (56\% of patients) and depression (46\%) were the two most common conditions for which support in counseling centers was sought (Perez-Rojas et al., 2017).

The increased rate of anxiety and depression symptoms in university settings has been attributed to a variety of life events that pose novel challenges for young adults transitioning to traditional college settings. This transition often involves becoming isolated from lifelong social relationships and support mechanisms, incurring extensive financial burden, and realizing limitations to academic proficiency in a more rigorous learning environment (Vredenburg et al., 1988). Confronting these myriad stressors while being removed from established supports is often exacerbated by the reality that many college students have not developed effective problem-focused 
coping strategies to manage the perceived stressors (Downs and Ashton, 2011; Heller and Cassady, 2017).

As individuals' perceptions of the stressors in their environment grow increasingly more negative and insurmountable, the overall perspective toward the environment, stressor, and self can become negative and lead to maladaptive coping strategies (Thomas et al., 2017). This maladaptive form of thinking is consistent with recent writings by Beck and Bredemeier (2016), who argue that while there are many biological and psychological mechanisms defining the depression-prone person, the disorder emerges only in the wake of a "precipitating loss of the investment in a vital resource" (pg. 601). Following this line of reasoning, in the current context of skyrocketing college expenses coupled with a challenging post-graduation market, students in higher education may well be at greater risk for hopelessness and depression than ever before.

The impact of depression for college students covers several domains of effective functioning and can lead to significant negative outcomes both academically and psychologically. Students with depressive symptoms may experience difficulty sleeping, changes in weight, and an increased likelihood of suicidal thoughts in addition to problems with academic learning (American Psychiatric Association, 2000). Learning challenges associated with depression include diminished levels of interest in school, difficulty paying attention or concentrating on tasks, and struggling to engage in positive academic behaviors such as attending class and studying (Gaspar de Matos et al., 2008). In addition, high rates of comorbid anxiety symptoms are noted with depression (e.g., Anderson and Hope, 2008), with the presence of an anxiety disorder routinely being associated with heightened rates of diagnosed depression (Wittchen et al., 1994; American Psychiatric Association, 2000; Gaspar de Matos et al., 2008; Horn and Wuyek, 2010). Research examining the effect of anxiety and depression has demonstrated that individuals who experience both conditions experience significantly lower levels of psychological health, higher rates of reoccurrence, longer durations of episodes with symptoms, greater resistance to treatment, and increased rates of suicidal attempts (Garber and Weersing, 2010; Rhebergen et al., 2011).

Attempting to explain the co-occurrence of anxiety and depression, as well as effectively differentiate between the two conditions, has generated considerable discussion in both theoretical and practical settings. The Content Specificity Hypothesis was an early influential theory attempting to identify methods for differentiating depression and anxiety (Beck et al., 1987). A basic tenant of the hypothesis is that while both groups generate negative appraisals of the future, the nature and severity of those projections differ. The theory proposes that individuals with high levels of anxiety tend to hold probabilistic statements about negative outcomes whereas those with high levels of depression hold absolute predictions of negative outcomes (Burns and Eidelson, 1998). Miranda and Mennin (2007) confirmed this trend in a study examining college students' projections for future outcomes, revealing that students with either anxiety or depression endorsed likely negative events in their futures. However, a distinction between these two groups was detected when looking to potential positive outcomesthose with depression were unable to provide positive future projections, while those with anxiety were. Loneliness has been proposed as another factor that is useful in distinguishing among anxious and depressed students, wherein those with depression tend to report higher levels of loneliness (Ebesutani et al., 2015).

An alternative explanation for differences among individuals with anxiety, depression, and those with both conditions has centered on a tripartite model that identifies the impacts of negative affect (NA), positive affect (PA), and physiological hyperarousal (PH; Clark and Watson, 1991; Joiner et al., 1996). In that model, anxious and depressed individuals both experience high levels of negative affect, which is characterized by feelings such as distress, worry, and fear (Clark and Watson, 1991; Watson et al., 1995). However, a distinction between anxiety and depression can be seen in the manifestation of the other two components in the model. Individuals with depression hold high levels of NA while maintaining low levels of PA (e.g., feeling energized, active, interested, joyful) - which is consistent with the projective statements observed by Miranda and Mennin (2007). Conversely, learners with anxiety hold high levels of both NA and PH (e.g., tension, dizziness, shortness of breath; Clark and Watson, 1991). Classification and prediction models with college samples illustrated this approach effectively parsed individuals with anxiety and depression-as well as explaining the high incidences of overlap in the two constructs (Watson et al., 1995; Joiner, 1996). Confirmatory evidence of this trend can be seen in more recent studies that substituted $\mathrm{PH}$ with fear, such that anxious learners have high NA and high fear (Chorpita et al., 1998, 2000).

While the tripartite theory and content specific hypothesis were designed primarily to identify clinical populations of depression and anxiety, more general orientations toward human experience have been offered to identify personality constructs that influence human outcomes in standard populations and conditions. One popular and commonly used theory of personality over the past several decades is the Big Five Factors of Personality (e.g., Costa and McCrae, 1992; John and Srivastava, 1999), which has been used extensively to show meaningful relationships among the five factors of personality (Neuroticism, Agreeableness, Extraversion, Conscientiousness, and Openness) and outcomes in personal life, work, and school (e.g., BenetMartinez and John, 1998; John et al., 2008). Most research on the Big Five theory related to depression and anxiety centers largely on the Neuroticism factor which captures an individual's tendency to experience negative emotional states (e.g., anxiety, anger, envy, depressed mood), respond poorly to environmental stress, and have a greater risk of internalizing mental disorders, including depression and anxiety (Lahey, 2009; Rothen et al., 2009; Sutton et al., 2011). Recent meta-analytic work examining 175 studies with attention to the Big Five and anxiety and depression confirmed that Neuroticism was key in identifying the presence of depression and anxiety symptoms ranging from generalized anxiety to specific phobias (Kotov et al., 2010). Consistent with this trend, research continues to suggest Neuroticism may serve as a general or broad indicator of psychological malady that is merely manifested in diverse 
ways for individuals who present with anxiety, depression, or other negative affective disorders-explaining the high rates of comorbidity in diagnoses (Barlow et al., 2013).

\section{Academic Anxieties}

Academic anxiety is a broad construct covering anxieties related to typical academic activities. Fear of lower performance compared to one's peers, worry about handling responsibilities, and experiencing stress in classrooms are basic components (Cassady, 2010). The construct of academic anxiety has been suggested primarily as a generalized form of various specific forms of anxiety in school settings (e.g., test or evaluation anxiety, computer anxiety, math anxiety, statistics anxiety; Cassady, 2010). Although the construct has a long theoretical history, there has been no established or consistent empirical program of research examining this broader dimension. The roots of this discipline can be traced to the 1960s, when Alpert and Haber (1960) were expanding early views of test anxiety by proposing academic anxieties were composed of both facilitative and debilitative features, consistent with traditional views of stress and performance popularized in the Yerkes-Dodson principle (Yerkes and Dodson, 1908). These representations formed the foundation of contemporary views of test anxiety (e.g., Sarason, 1986; Zeidner and Matthews, 2005; Cassady, 2010; Ramirez and Beilock, 2011), which is the more commonly explored domain of inquiry. However, the point of differentiation to be made is that academic anxiety need not be centered on an evaluative event, with a myriad of academic stressors other than tests leading to similar anxious responses (Cassady, 2010). Collectively, these models assert facilitative anxiety occurs when there is a relatively small amount-or manageable degree-of stress related to an academic situation that initiates drive and motivation to support optimal performance. When the level of stress exceeds the coping strategies available to the learner, the contextual stressors can overwhelm perceived control in the event and become debilitating (Keeley et al., 2008).

We propose that cognitive test anxiety is specific form of academic anxiety that (when elevated) interferes with optimal academic functioning in various academic contexts along the learning-testing cycle (Cassady and Johnson, 2002). Built from the "worry" component classic models of test anxiety (e.g., Liebert and Morris, 1967), manifestations of cognitive test anxiety include debilitative internal dialog, cognitive interference, and reduced cognitive efficiency during test preparation and test performance contexts (see Cassady, 2004a, 2010). These manifestations may include worry over test failure, self-deprecating ruminations, distracting social comparisons, and difficulties with working memory efficiency in evaluation situations (Eum and Rice, 2011; Ramirez and Beilock, 2011; Thomas et al., 2018), which can lead to retention issues during preparation and affect retrieval during examseven in cases with no external evaluative pressure (Cassady, 2004b). These inefficiencies and interferences lead to negative outcomes in performance, exacerbate feelings of anxiety, and may be the avenue for students' increased levels of depressive symptoms (Zunhammer et al., 2013). Estimates of the rates of incidence of test anxiety have varied over the years-but recent estimates from valid resources suggest that $\sim 40-60 \%$ of students likely experience test anxiety (Ergene, 2003; Segool et al., 2013 ) but only $\sim 15 \%$ experience test anxiety to a debilitating degree (Putwain and Daly, 2014).

While cognitive test anxiety has been demonstrated to explain meaningful levels of learner performance, the construct is highly specific and may not generalize to non-testing contexts (e.g., writing papers, homework, class activities). Although it makes logical sense that the notion of "academic anxiety" is a broader construct that would be hierarchically superordinate to test anxiety, there is limited empirical work to validate this representation. We predict that these two constructs are indeed related, with academic anxiety representing a broader dimension of school-related anxiety experiences for learners than the welldocumented concept of test anxiety. Furthermore, consistent with the broader representation of neuroticism as an overarching emotional response construct, we believe that both of these specific forms of academic-related anxieties are subordinately related to general anxiety symptoms.

\section{Current Investigation}

The purpose of the current study was to examine the relationships among neuroticism and academic anxieties as well as identify the utility of those measures for predicting levels of depression in college students. Specifically, the study was designed to identify if academic anxiety and cognitive test anxiety provided unique explanatory power to the level of student-reported depressive symptomology after accounting for general neuroticism. In addition, this study also explored whether cognitive test anxiety was distinguishable from the broader construct of academic anxiety, and provides additional information with respect to the prediction of depressive symptoms. Finally, the study was used to document the reliability and validity the Academic Anxiety Scale, which has not been reported in prior literature.

We hypothesized that the indicators of anxiety, including Neuroticism, academic anxiety, and cognitive test anxiety would be "nested" forms of anxiety, in that Neuroticism is the superordinate personality dimension related to anxiety, with academic anxiety and cognitive test anxiety serving as specific subcomponents of this broad dimension. We also anticipated that the academic anxiety indicators would provide additional explained variance (beyond that explained by Neuroticism) to the prediction of depression symptoms in college students.

\section{METHOD}

\section{Participants}

Data were collected from 145 participants from a public Midwestern university research pool across two consecutive academic semesters. Following listwise deletion of missing data for three participants, 142 subjects remained for analyses. Participant demographics were typical for the population from which the research pool draws (primarily female and Caucasian). Final demographic distributions were predominantly female ( $n$ $=122$ ), with limited diversity in the sample (self-reported White $=126$, Black $=7$, Asian $=4$, and "Other" =4). The sample also 
had a higher number of upperclassmen (again, consistent with the population pool); specifically, 15 freshmen, 25 sophomores, 56 juniors, and 45 seniors completed the study.

\section{Materials}

\section{The Beck Depression Inventory, 2nd Edition (BDI-II)}

The Beck Depression Inventory-2nd Edition (BDI-II) is the revision to the Beck Depression Inventory. The BDI-II is a 21-item self-report instrument measuring depressive symptomatology on a single continuum. The measure is reported to have excellent psychometric properties, including high internal consistency ( $a=0.92$ ), evidence of content validity based on the Diagnostic and Statistical Manual of Mental Disorders, 4th edition (Beck et al., 1996), and lack of racial bias in public university settings (Sashidharan et al., 2012). In addition to the reliability and validity data presented in the manual for its use (Beck et al., 1997), its use for measuring symptoms of depression in college students and the revision has been independently replicated (Whisman et al., 2000; Storch et al., 2004). The Beck Depression Inventory and its successors are among the most frequently used measures in clinical settings (Lezak et al., 2004). Although the BDI-II includes a system for placing individuals into qualitative categories of severity, this function is primarily for communication among clinicians and was not used for the present study. The data collected with the current sample demonstrated strong internal consistency once again $(a=0.916)$.

\section{The Cognitive Test Anxiety Scale-Revised (CTAR)}

The CTAS was originally developed by Cassady and Johnson (2002) as a measure of the cognitive dimension of trait test anxiety, building upon the traditional construct of "worry" in classic representations of test anxiety (Liebert and Morris, 1967; Sarason, 1988). The CTAR reflects revisions made to the original CTAS based on a series of measurement studies attempting to validate the scale in different cultures and languages (e.g., Furlan et al., 2009; Baghei and Cassady, 2014). The primary adaptation reflected by the CTAR was the elimination of reverse-coded items that improved scale coherence and the inclusion of items that identify cognitive aspects of test anxiety during all three phases of the learning-testing cycle. Validation studies demonstrated the CTAR maintains strong construct validity (Cassady and Finch, 2015), and the current sample revealed strong internal consistency, $a=0.970$.

\section{The Big Five Inventory (BFI)}

The Big Five Inventory (BFI) is a 44-item self-report measure that generates five factors that are consistent with empirical and clinical interpretations of the five-factor model of personality (John et al., 1991, 2008; Benet-Martinez and John, 1998; Lahey, 2009). For the purposes of this investigation, we primarily responses to the Neuroticism subscale, which includes 8 items with strong internal consistency ( $a=0.87$ ), which was confirmed in this sample with a Cronbachs alpha of.868.

\section{Academic Anxiety Scale}

Twenty 4-point Likert-type items were developed to represent a cross-section of worries and fears in academic environments and situations. Response options were identical to the CTAR (" $1=$ Not at all typical of me," $2=$ Somewhat typical of me," " $3=$ Quite typical of me," and " 4 = Very typical of me"). The underlying goal of this scale was to generate a simplified broad contextual representation for anxieties experienced within academic settings (see Cassady, 2010). Psychometric properties of the Academic Anxiety Scale were not established prior to this study, and are addressed in the forthcoming analyses.

\section{Demographic Information Form}

Students also completed a short demographic questionnaire that included self-reported GPA, Scholastic Aptitude Test scores, gender, year in school, and race.

\section{Procedures}

Participants completed all measures during small group sessions $(n<15)$ they selected from several available options. Participation in this study was one option of several to satisfy a credit requirement in one of their courses. Two doctoral students in a School Psychology program with training on administering psychometric measures, including the BDI-II, conducted the data collection sessions in standard university classrooms. This study, along with all materials and procedures, was approved by the Ball State University IRB (whose procedures are aligned and overseen by the U.S. Office for Human Research Protections and the Belmont Report). All participants in the study provided informed written consent to participate in the study. To ensure this, the data collection members first provided both verbal and written information explaining all aspects of their participation before the written consent was provided. Following the written informed consent, participants completed the measures in the following order: Demographics Form, CTAR, Academic Anxiety Scale, BFI, and the BDI-II. The order was fixed to ensure that the BDI-II was completed last to ensure that any participants with elevated levels of depressive concerns could be referred to a free counseling center immediately, per study protocol and Institutional Review Board requirement. No participants in the study were referred for this immediate counseling support, expressed concern to the data collection team, or contacted the licensed psychologist provided in their study debrief materials.

\section{Planned Analyses}

First, an exploratory factor analysis (EFA) was conducted to identify the optimal factor structure for the newly created Academic Anxiety Scale (AAS). Based on the EFA results, qualitative examination of the plausible factors generated, quantitative item characteristics, and qualitative examination of individual items, the proposed AAS was used in subsequent analyses.

Second, a planned four-step hierarchical multiple linear regression (HLR) model was tested to evaluate whether academic anxieties were contributing factors to levels of reported depression among college students beyond the anxiety measure used in this study (the BFI Neuroticism subscale). Due to limited evidence of heteroscedasticity, a robust procedure called "Wild bootstrap" (Liu, 1988) was implemented to calculate the final hierarchical model coefficients. Finally, exploratory descriptive 
analyses were used to examine the interrelated nature of the anxiety constructs in this study.

\section{RESULTS}

\section{Exploratory Factor Analysis of the Academic Anxiety Scale (AAS)}

Principal Axis Factoring with Direct Oblimin rotation was used in the Exploratory Factor Analysis (EFA). Initial review of the EFA revealed that four factors had eigenvalues $>1$. The Very Simple Structure (VSS) analysis indicated a two-factor solution was slightly better than the one-factor solution (see Figure "VSS"), with both of those being superior to three- and fourfactor solutions. On the other hand, Velicer's Minimum Average Partial indicated the one-factor solution was best, followed by the three- and two-factor solutions.

Review of the initial four factors generated in the EFA demonstrated that viable interpretations could be attributed to each of the factors. The first factor (12 items) represented the overarching Academic Anxiety construct of interest; this was significantly larger than the others, accounting for $37 \%$ of the variance among the 20 items. The other three factors represented social anxieties manifested in the classroom, attitudes regarding the importance of school, and parental and peer pressures to perform. These factors loaded on only 2-3 items each, accounting for $23 \%$ of the variance collectively. Although these factors appeared to describe valid constructs, they were not constructs of interest (more consistent with alternative constructs such as perfectionism). Thus, the items that loaded on factors 2, 3, and 4 were removed from future analyses. Finally, one additional item loading on the first factor ("My instructors seem to think I am not very smart.") was noted to have higher skew and lower variance than the other items and also to be less directly connected to individual students' personal interpretations of academic stressors. These attributes contributed to the item's relatively weak discrimination among students, and this item was removed, resulting in an 11-item unitary scale. Review of the final items demonstrate conformity with the initial intention of the scale construction-to generate a short assessment of learners' identification with academic stressors. Item commonalities were all at least acceptable (see Table 1 for item information). Reliability estimates were high, with Guttman's split-half reliability at.91 and Cronbach's alpha at.90 for the final 11-item scale.

\section{Hierarchical Linear Regression Analysis}

Hypotheses focused on the "nested" nature of progressively specific dimensions of anxiety (general neuroticism, academic anxiety, cognitive test anxiety) were tested with a hierarchical linear regression analysis in four steps. The first step addressed primary demographic variables of particular interest (gender, race, age). The second step added the broad measure of anxiety captured by the BFI Neuroticism subscale. Subsequently, responses to the Academic Anxiety Scale and CTAR were added in steps 3 and 4 to identify any additional explained variance that may predict depression (see Table 2).
TABLE 1 | Item analysis of the academic anxiety scale $(N=142)$.

\begin{tabular}{|c|c|c|c|}
\hline Item & $M$ & $S D$ & Commonality \\
\hline $\begin{array}{l}\text { I often worry that my best is not as good } \\
\text { as expected in school. }\end{array}$ & 2.65 & 1.09 & 0.344 \\
\hline $\begin{array}{l}\text { I tend to put off doing school work } \\
\text { because it stresses me. }\end{array}$ & 2.11 & 1.02 & 0.459 \\
\hline $\begin{array}{l}\text { I often worry that I am not doing } \\
\text { assignments properly. }\end{array}$ & 2.32 & 0.97 & 0.479 \\
\hline $\begin{array}{l}\text { I am less confident about school than my } \\
\text { classmates. }\end{array}$ & 1.99 & 0.99 & 0.661 \\
\hline $\begin{array}{l}\text { I have a sense of dread when I am in my } \\
\text { classrooms. }\end{array}$ & 1.59 & 0.8 & 0.649 \\
\hline I tend to find my instructors intimidating. & 1.73 & 0.8 & 0.6 \\
\hline $\begin{array}{l}\text { I spend much of my time at school } \\
\text { worrying about what is next. }\end{array}$ & 2.04 & 1.03 & 0.571 \\
\hline $\begin{array}{l}\text { There is something about school that } \\
\text { scares me. }\end{array}$ & 1.73 & 0.95 & 0.524 \\
\hline $\begin{array}{l}\text { I'm concerned about what my classmates } \\
\text { think about my abilities. }\end{array}$ & 2.05 & 1.03 & 0.388 \\
\hline $\begin{array}{l}\text { I often feel sick when I need to work on a } \\
\text { major class assignment. }\end{array}$ & 1.74 & 0.96 & 0.451 \\
\hline $\begin{array}{l}\text { I have a hard time handling school } \\
\text { responsibilities. }\end{array}$ & 1.68 & 0.9 & 0.55 \\
\hline
\end{tabular}

Examination of the assumptions for the regression procedure revealed the standard model was at risk for heteroscedasticity. Therefore, we employed a "Wild bootstrap" procedure developed by Liu (1988), which has been demonstrated to improve regression models with heteroscedastic errors at relatively low cost to power. As such, the final model parameter estimates presented below reflect the adjustment enabled by substituting this procedure for the a priori parametric analysis.

The results of the hierarchical regression demonstrated that the demographic variables did not independently account for any meaningful variance in depression scores (as measured by the BDI-II). In the second step, depression was reliably predicted by Neuroticism, with gender demonstrating a small influence as expected (total $R^{2}=0.37$; see Table 2). In Step 3, the addition of academic anxiety and cognitive test anxiety significantly added to the model's predictive power $\left(R^{2}=0.48, \Delta R^{2}=0.11\right)$, however the additional explained variance was attributed to academic anxiety. In the final step, we included the remaining factors from the BFI to ensure that personality variables did not overtake the anxiety indicators in identifying depressive symptomology. The addition of those variables did provide a statistically significant change in overall explained variance-but the results did not identify any changes to the primary observations regarding anxiety indicators and prediction of depression (total $R^{2}=0.53$ ).

\section{Descriptive Statistics}

A final review of the correlations among the variables was undertaken to provide some additional insight into the results of the regression analysis. The use of the hierarchical regression was considered optimal to allow a controlled test of the nested nature of the anxiety dimensions. However, the downside to that approach is when the constructs share significant 
TABLE 2 | Hierarchical linear regression analysis predicting college students' depressive symptomatology $(N=141)$.

\begin{tabular}{|c|c|c|c|}
\hline Variable & $\beta$ & $t$ & $R^{2}$ \\
\hline Step 1 & & & 0.02 \\
\hline Gender & -0.126 & -1.47 & \\
\hline Race & -0.086 & -1.01 & \\
\hline Age & 0.028 & 0.34 & \\
\hline Step 2 & & & 0.37 \\
\hline Gender & -0.208 & $-2.90^{\star \star}$ & \\
\hline Race & -0.025 & -0.37 & \\
\hline Age & 0.041 & 359 & \\
\hline Neuroticism & 0.600 & $8.66^{\star \star \star}$ & \\
\hline Step 3 & & & 0.48 \\
\hline Gender & -0.177 & $-2.74^{\star \star}$ & \\
\hline Race & -0.049 & -0.76 & \\
\hline Age & 0.004 & 0.06 & \\
\hline Neuroticism & 0.394 & $5.25^{\star \star \star}$ & \\
\hline Academic Anxiety & 0.295 & $2.80^{\star \star}$ & \\
\hline Cognitive Test Anxiety & 0.109 & 1.08 & \\
\hline Step 4 & & & 0.53 \\
\hline Gender & -0.130 & $-2.00^{\star}$ & \\
\hline Race & -0.046 & -0.74 & \\
\hline Age & 0.028 & 0.46 & \\
\hline Neuroticism & 0.315 & $3.70^{\star \star \star}$ & \\
\hline Academic Anxiety & 0.264 & $2.57^{\star \star}$ & \\
\hline Cognitive Test Anxiety & 0.140 & 1.40 & \\
\hline Extraversion & 0.005 & 0.07 & \\
\hline Agreeableness & -0.195 & $-2.78^{\star \star}$ & \\
\hline Conscientiousness & -0.104 & -1.53 & \\
\hline Openness & 0.153 & $2.36^{\star}$ & \\
\hline
\end{tabular}

Step $2 \Delta R^{2}=0.348, p<0.001 ;$ Step $3 \Delta R^{2}=0.107, p<0.001 ;$ Step $4 \Delta R^{2}=0.055$, $p=0.006$.

${ }^{*} p<0.05,{ }^{* *} p<0.01,{ }^{* * *} p<0.001$.

variance (e.g., cognitive test anxiety and academic anxiety), the regression results may mask the utility of all the related measures. A brief review of the correlations merely helps center the results within the broader context of these varied affective variables.

The correlational table largely confirmed the expectation that these variables were strongly related, with the greatest noted connection between cognitive test anxiety and academic anxiety (Table 3). This finding suggests that while cognitive test anxiety may very well be a more contextually-specific measure for a distinct academic anxiety, there is likely little to be gained through using both measures to identify specific aspects of anxiety with university students. Interestingly, the correlational patterns identify that cognitive test anxiety was the measure most highly correlated with GPA, with academic anxiety and depression sharing weak to moderate correlations with students' self-reported GPA. Neuroticism was not found to correlate with GPA. We find these patterns interesting, and they may point to a continued line of inquiry exploring the differences in the connections between GPA and general neuroticism as compared to specific academic anxieties, and
TABLE 3 | Correlation summary table.

BDI-II Neuroticism $\begin{gathered}\text { Academic } \\ \text { Anxiety }\end{gathered} \begin{gathered}\text { Cognitive } \\ \text { Test Anxiety }\end{gathered}$

\begin{tabular}{lllll}
\hline BDI-II & & & & \\
Neuroticism & $0.575^{\star \star}$ & & & \\
Academic Anxiety & $0.586^{\star \star}$ & $0.510^{\star \star}$ & & \\
Cognitive Test Anxiety & $0.504^{\star *}$ & $0.445^{\star \star}$ & $0.777^{\star \star}$ & \\
GPA & $-0.231^{\star}$ & -0.013 & $-0.272^{\star}$ & $-0.407^{\star \star}$ \\
\hline
\end{tabular}

${ }^{\star} p<0.01 ;{ }^{* *} p<0.001$.

highlight once again the potential value of using academic anxiety assessments to identify learners who may need academic or emotional support.

\section{DISCUSSION}

The results of this study provide useful contributions in three primary aspects. First, reliability and validity information on the newly formulated Academic Anxiety Scale indicates the measure can be used effectively to assess stressors perceived by learners in university settings that characterize academic anxiety. Second, academic anxiety was found to be a significant factor in predicting depression among college students-adding explanatory power beyond the overarching construct of neuroticism. Third, preliminary evidence was identified to support the notion of a "nested" representation of anxiety indicators, where academic anxieties are hierarchically subordinate to the more general indications of neuroticism or anxiety.

\section{Prediction of Depression}

The results expand the literature regarding the important links between anxiety and depression for university learners. We propose these results suggest that elevated levels of perceived stress or threat in response to academic stressors may serve as an early detection indicator to help identify learners at risk for academic failure and/or depression symptoms. Considering the complex range of stressors facing undergraduate learners (Heller and Cassady, 2017), attention to a contextually relevant marker for academic stress may be a meaningful area of focus when considering support mechanisms for undergraduate students, who are known to be vulnerable to higher rates of depression (Whisman and Richardson, 2015). The attention to unique factors of academic stressors and anxiety for college is an avenue of considerable utility to campus leaders, as the number of learners who will present with depressive symptoms routinely increases during the college years (Perez-Rojas et al., 2017). Given the reality that many college learners become disconnected from emotional and academic support mechanisms that have traditionally helped buffer the impact of academic anxieties (Vredenburg et al., 1988), it is critical to raise attention to relevant indicators that may alert university support resources to those learners who are at risk for academic failure or depression. 


\section{The Place of Academic Anxiety}

Our long-range goal for developing a measure of academic anxiety is to highlight for educators and support personnel in educational settings a general set of characteristics that are commonly reported as stressors that tend to be interpreted as threatening by learners. While considerable attention has been devoted to negative impacts of specific forms of anxiety in school contexts (e.g., test anxiety, computer anxiety, foreign language, science, math; Cassady, 2010), we assert it is advantageous to provide practitioners with a more generalized set of indicators and interventions. To that effort, we define academic anxiety as a generalized representation of perceived threat imposed by a stressor encountered within any academic task, setting, or context (Schniering and Rapee, 2004; Cassady, 2010; Beck and Bredemeier, 2016). Identification of a general representation for "academic anxiety" may help build a greater level of attention among student support personnel to identify and treat elevated levels of anxiety in academic settings. This study provides a first step in validating a measure of academic anxiety, and demonstrating that it is strongly related to test anxiety and general neuroticism, predicts depression symptoms, and has a weak to moderate association with college GPA. We believe that attention to a more general representation of academic anxiety symptoms and behaviors may help university educators and support staff recognize that students suffer from academic anxiety in contexts beyond merely evaluative situations. The empirical link between academic anxiety and depression symptoms identified in this study highlights the value of raising attention to this construct.

The results of this study also provide initial support for this general-to-specific representation for indicators of anxiety in learners. As expected, we identified expectedly high correlations among cognitive test anxiety, academic anxiety, and neuroticism. However, in addition to these simple correlational findings, the data reviewed from a collective perspective indicate that the 3 anxiety measures used in this study diverged from one another. We interpret the results of this study as supporting a "nested" or hierarchical representation for anxiety constructs, where test anxiety is subordinate to academic anxiety, which is in turn subordinate to neuroticism. This conclusion is necessarily tentative given the limited data available to date, but is consistent with contemporary and historical representations that address the relationships among forms of anxiety, which have repeatedly demonstrated overlaps among neuroticism, test anxiety, and trait anxiety (e.g., Gordan and Sarason, 1955; Chamorro-Premuzic et al., 2008; Thomas et al., 2018).

\section{Practical Implications}

Resetting these findings in the broader context of the high rates of co-occurrence of depression and anxiety, particularly in young adults (Keyes, 2006) provides some insight into the potential utility for identifying individuals with elevated levels of academic anxiety in college settings. As articulated in the content specific hypothesis (e.g., Beck et al., 1987) and the tripartite model (e.g., Clark and Watson), there is considerable overlap in the perception of likely negative future outcomes for individuals with anxiety and/or depression. In addition to those potential negative outcomes, anxious learners also are prone to physiological hyperarousal or maintaining a fearful perspective (Chorpita et al., 2000). However, a more critical picture can be observed for learners with depression, where not only do they project negative future outcomes, they are incapable of identifying potential positive outcomes (e.g., Miranda and Mennin, 2007). Identification of academic anxiety may be highly advantageous to early intervention efforts, where the support personnel in higher education institutions can support learners dealing with potential negative outcomes and heightened fear responses to academic settings. These early intervention attempts are likely to help reduce progressively more severe incidents of anxiety or depression for many learners, as they access support strategies that help them cope with the stressors in their academic environment (Von der Embse et al., 2018). If these supports are not achieved early on, growing levels of constant stress, fear of negative outcomes, and perceptions of likely failure may exacerbate negative emotional responses-giving way to hopelessness, withdrawal, or depression.

This early identification goal follows in a line of prior work that found treating anxiety symptoms was useful for mitigating future incidences of depression (Costello et al., 2003; Garber and Weersing, 2010). The use of a general screening instrument for academic anxiety has also been advocated for by experts attending to the detection of specific anxieties so that more prescriptive and effective interventions can be leveraged to support student success (Von der Embse et al., 2013).

\section{Limitations and Future Directions}

The most obvious and significant limitation of this study is the limitation in generalizability imposed by the available sampleboth in sample size and representation of diverse groups. Our attempt to statistically mitigate this limitation helped ensure that reliable analyses could be achieved, but this adjustment can be improved upon with replication studies that explore the "nested" hypothesis of anxiety as well as the utility of academic anxiety in predicting depression. In addition, we recognize that a next logical step to validate the construct is to explore academic anxiety in younger age groups (e.g., children, adolescents) to see if the pattern of results observed here translates to different contexts.

Regarding future opportunities that may expand from this early work, we see several viable avenues. First, given the simple nature of the 11-item Academic Anxiety Scale, we see potential for both practitioners and researchers alike in identifying individuals at risk for negative responses to academic stressors, in a "screening" model similar to that proposed by experts regarding test anxiety (Von der Embse et al., 2013). The potential advantage for the use of a more general measure of academic anxiety (as compared to test anxiety) is the ability to expand the contextual factors that may trigger anxious response in academic settings beyond preparation and performance for evaluative events.

Second, if continued work on a nested representation for academic anxieties validates our representation that general indicators of anxiety are hierarchically superordinate to academic anxiety and cognitive test anxiety, testing intervention strategies 
that center on the particular locus of perceived stressors may become progressively more prescriptive and effective. That is, rather than attempting to help anxious learners with a test anxiety strategy, evidence may arise that the learner does not perceive tests as threatening-but the perhaps the source of anxiety rests in the classroom setting or working on homework in isolation. With a greater precision in identifying the source of the anxiety, there can be greater success in supporting students to reach positive outcomes. Related to this, we believe that a growing awareness of educational professionals to the reality that stressors that exceed the individuals' coping resources can be centered on academic events or settings that go well beyond testing events. With this more generalized representation for academic anxiety, teachers and support personnel may be more attuned to identifying and supporting negative affective

\section{REFERENCES}

Alpert, R., and Haber, R. N. (1960). Anxiety in academic achievement situations. J. Abnorm. Soc. Psychol. 10, 207-215. doi: 10.1037/h0045464

American Psychiatric Association, 2000 American Psychiatric Association (2000). Diagnostic and Statistical Manual of Mental Disorders. 4th edn. Washington, DC: American Psychiatric Association.

Anderson, E. R., and Hope, D. A. (2008). A review of the tripartite model for understanding the link between anxiety and depression in youth. Clin. Psychol. Rev. 28, 275-287. doi: 10.1016/j.cpr.2007.05.004

Baghei, P., and Cassady, J. C. (2014). Validation of the persian translation of the cognitive test anxiety scale. SAGE Open 4, 1-11. doi: $10.1177 / 2158244014555113$

Barlow, D. H., Sauer-Zavala, S., and Carl, J. R. (2013). The nature, diagnosis, and treatment of neuroticism: back to the future. Clin. Psychol. Sci. 2, 344-365. doi: $10.1177 / 2167702613505532$

Beck, A. T., and Bredemeier, K. (2016). A unified model of depression: integrating clinical, cognitive, biological, and evolutionary perspectives. Clin. Psychol. Sci. 4, 596-619. doi: $10.1177 / 2167702616628523$

Beck, A. T., Brown, G., Steer, R. A., Eidelson, J. I., and Riskind, J. H. (1987). Differentiating anxiety and depression: a test of the cognitive content-specificity hypothesis. J. Abnorm. Psychol. 96, 179-183. doi: 10.1037/0021-843X.96.3.179

Beck, A. T., Guth, D., Steer, R. A., and Ball, R. (1997). Screening for major depression disorders in medical inpatients with the Beck Depression Inventory for Primary Care. Behav. Res. Therapy 35, 785-791.

Beck, A. T., Steer, R. A., and Brown, G. K. (1996). Manual for the Beck Depression Inventory-II. San Antonio, TX: Psychological Corporation.

Benet-Martinez, V., and John, O. P. (1998). Los Cinco Grandes across cultures and ethnic groups: multitrait multimethod analyses of the big five in Spanish and English. J. Pers. Soc. Psychol. 75, 729-750. doi: 10.1037/0022-3514.75.3.729

Burns, D. D., and Eidelson, R. J. (1998). Why are depression and anxiety correlated? a test of the tripartite model. J. Consult. Clin. Psychol. 66, 461-473. doi: 10.1037/0022-006X.66.3.461

Cassady, J. C. (2004b). The impact of cognitive test anxiety on text comprehension and recall in the absence of salient evaluative pressure. Appl. Cogn. Psychol. 18, 311-325. doi: 10.1002/acp.968

Cassady, J. C. (2010). Anxiety in Schools: The Causes, Consequences and Solutions for Academic Anxieties. New York, NY: Peter Lang.

Cassady, J. C., and Finch, W. H. (2015). Using factor mixture modeling to identify dimensions of cognitive test anxiety. Learn. Individ. Differ. 41, 14-20. doi: 10.1016/j.lindif.2015.06.002

Cassady, J. C., and Johnson, R. E. (2002). Cognitive test anxiety and academic procrastination. Contemp. Educ. Psychol. 27, 270-295. doi: 10.1006/ceps.2001.1094

Cassady,. C. (2004a). The influence of cognitive test anxiety across the learningtesting cycle. Learn. Instr. 14, 569-592. doi: 10.1016/j.learninstruc.2004.09.002

Chamorro-Premuzic, T., Ahmetoglu, G., and Furnham, A. (2008). Little more than personality: dispositional determinants of test anxiety (the Big Five, responses by learners in educational contexts that have no explicit performance assessment events.

\section{ETHICS STATEMENT}

This study was carried out in accordance with the recommendations of the University's Institutional Review Board with written informed consent from all subjects. All subjects gave written informed consent in accordance with the federal guidelines.

\section{AUTHOR CONTRIBUTIONS}

All authors listed have made a substantial, direct and intellectual contribution to the work, and approved it for publication.

core self-evaluations and self-assessed intelligence). Learn. Individ. Differ. 18, 258-263. doi: 10.1016/j.lindif.2007.09.002

Chorpita, B. F., Albano, A. M., and Barlow, D. H. (1998). The structure of negative emotions in a clinical sample of children and adolescents. J. Abnorm. Psychol. 107, 74-85. doi: 10.1037/0021-843X.107.1.74

Chorpita, B. F., Daleiden, E. L., Moffitt, C., Yim, L., and Umemoto, L. A. (2000). Assessment of tripartite factors of emotion in children and adolescents I: structural validity and normative data of an affect and arousal scale. $J$. Psychopathol. Behav. Assess. 22, 141-160. doi: 10.1023/A:1007584423617

Clark, L. A., and Watson, D. (1991). Tripartite model of anxiety and depression: psychometric evidence and taxonomic implications. J. Abnorm. Psychol. 100, 316-336. doi: 10.1037/0021-843X.100.3.316

Costa, P. T., and McCrae, R. R. (1992). Normal personality assessment in clinical practice: the NEO personality inventory. Psychol. Assess. 4, 5-13. doi: 10.1037/1040-3590.4.1.5

Costello, E. J., Mustillo, S., Erkanli, A., Keeler, G., and Augold, A. (2003). Prevalence and development of psychiatric disorders in childhood and adolescence. Arch. Gen. Psychiatry 60, 837-844. doi: 10.1001/archpsyc. 60.8 .837

Downs, A., and Ashton, J. (2011). Vigorous physical activity, sports participation, and athletic identity: implications for mental and physical health in college students. J. Sport Behav. 34, 228-249. Available online at: https://psycnet.apa. org/record/2011-17095-002

Ebesutani, C., Fierstein, M., Viana, A. G., Trent, L., Young, J., and Sprung, M. (2015). The role of loneliness in the relationship between anxiety and depression in clinical and school-based youth. Psychol. Sch. 52, 223-234. doi: $10.1002 /$ pits. 21818

Ergene, T. (2003). Effective interventions on test anxiety reduction: a metaanalysis. Sch. Psychol. Int. 24, 313-328. doi: 10.1177/01430343030243004

Eum, K., and Rice, K. G. (2011). Test anxiety, perfectionism, goal orientation, and academic performance. Anxiety Stress Coping 24, 167-178. doi: 10.1080/10615806.2010.488723

Furlan, L. A., Cassady, J. C., and Perez, E. R. (2009). Adapting the cognitive test anxiety scale for use with argentinean university students. Int. J. Test. 9, 3-19. doi: 10.1080/15305050902733448

Garber, J., and Weersing, V. R. (2010). Comorbidity of anxiety and depression in youth: implications for treatment and prevention. Clin. Psychol. Sci. Practice 17, 293-306. doi: 10.1111/j.1468-2850.2010.01221.x

Gaspar de Matos, M., Tome, G., Borges, A. I., Manso, D., Ferreira, P., and Ferreira, A. (2008). Ansiety, depression and coping strategies: improving the evaluation and the understanding fo these dimensions during preadolescence and adolescence. J. Cogn. Behav. Psychother. 8, 169-184. doi: 10.5935/1808-5687.20090015

Gordan, E. M., and Sarason, S. B. (1955). The relationship between "test anxiety" and "other anxieties." J. Pers. 23, 317-323.

Heller, M. L., and Cassady, J. C. (2017). The impact of perceived barriers, academic anxiety and resource management strategies on achievement in first year community college students. J. First Year Exp. Stud. Trans. 29, 
9-32. Available online at: https://www.ingentaconnect.com/content/fyesit/ fyesit;jsessionid=1bmhkinl5lc8p.x-ic-live- 01

Horn, P. J., and Wuyek, L. A. (2010). Anxiety disorders as a risk factor for subsequent depression. Int. J. Psychiatry Clin. Pract. 14, 244-247. doi: 10.3109/13651501.2010.487979

John, O. P., Donahue, E. M., and Kentle, R. L. (1991). The Big Five InventoryVersions $4 a$ and 54. Berkeley, CA: University of California, Berkeley, Institute of Personality and Social Research.

John, O. P., Naumann, L. P., and Soto, C. J. (2008). "Paradigm shift to the integrative big-five trait taxonomy: history, measurement, and conceptual issues," in Handbook of Personality: Theory and Research, eds O. P. John, R. W. Robins, and L. A. Pervin (New York, NY: Guilford Press), 114-158

John, O. P., and Srivastava, S. (1999). "The big five trait taxonomy: history, measurement, and theoretical perspectives," in Handbook of Personality: Theory and Research, Vol. 2, eds L. A. Pervin and O. P. John (New York, NY: Guilford Press), 102-138.

Joiner, T. E., Jr., Catanzaro, S., and Laurent, J. (1996). Tripartite structure of positive and negative affect, depression, and anxiety in child and adolescent psychiatric inpatients. J. Abnorm. Psychol. 105, 401-409. doi: 10.1037/0021-843X.105.3.401

Joiner, T. E. Jr. (1996). A confirmatory factor-analytic investigation of the tripartite model of depression and anxiety in college students. Cognit. Ther. Res. 20, 521-539. doi: 10.1007/BF02227911

Keeley, J., Zayac, R., and Correia, C. (2008). Curvilinear relationships between statistics anxiety and performance among undergraduate students: evidence for optimal anxiety. Stat. Edu. Res. J. 7, 4-15. Available online at: https://psycnet. apa.org/record/2008-17676-001

Keyes, C. L. (2006). Mental health in adolescence: is Americ's youth flourishing? Am. J. Orthopsychiatry 76, 395-402. doi: 10.1037/0002-9432.76.3.395

Kotov, R., Gamez, W., Schmidt, F., and Watson, D. (2010). Linking "big" personality traits to anxiety, depressive, and substance use disorders: a metaanalysis. Psychol. Bull. 136, 768-821. doi: 10.1037/a0020327

Lahey, B. B. (2009). Public health significance of neuroticism. Am. Psychol. 64, 241-256. doi: 10.1037/a0015309

Lezak, M. D., Howieson, D. B., and Loring, D. W. (2004). "Tests of personal adjustment and emotional functioning pgs," in Theory and Practice of Neuropsychological Assessment-4th Edition (New York, NY: Oxford University Press), 738-754.

Liebert, R. M., and Morris, L. W. (1967). Cognitive and emotional components of test anxiety: a distinction and some initial data. Psychol. Rep. 20, 975-978. doi: $10.2466 /$ pr0.1967.20.3.975

Liu, R. Y. (1988). Bootstrap procedure under some non-I.I.D. models. Annals Stat. 16, 1696-1708. doi: 10.1214/aos/1176351062

Miranda, R., and Mennin, D. S. (2007). Depression, generalized anxiety disorder, and certainty in pessimistic predictions about the future. Cognit. Ther. Res. 31, 71-82. doi: 10.1007/s10608-006-9063-4

Perez-Rojas, A. E., Lockard, A. J., Bartholomew, T. T., Janis, R. A., Carney, D. M., Xiao, H., et al. (2017). Presenting concerns in counseling centers: the view from clinicians on the ground. Psychol. Serv. 14, 416-427. doi: 10.1037/ser0000122

Putwain, D., and Daly, A. L. (2014). Test anxiety prevalence and gender differences in a sample of English secondary school students. Educ. Stud. 40, 554-570. doi: 10.1080/03055698.2014.953914

Ramirez, G., and Beilock, S. (2011). Writing about testing worries boosts exam performance in the classroom. Science 331, 211-213. doi: 10.1126/science.1199427

Rhebergen, D., Batelaan, N. M., deGraaf, R., Nolen, W. A., Spijker, J., Beekman, A. T. F., et al. (2011). The 7-year course of depression and anxiety in the general population. Acta Psychiatr. Scand. 123, 297-306. doi: 10.1111/j.1600-0447.2011.01677.x

Rothen, S., Vandeleur, C. L., Lustenberger, Y., Jeanprêtre, N., Ayer, E., Fornerod, D., et al. (2009). Personality traits in children of parents with unipolar and bipolar mood disorders. J. Affect. Disor. 113, 133-141. doi: 10.1016/j.jad.2008.05.013

Sarason, I. G. (1986). Test anxiety, worry, and cognitive interference. in Self-Related Cognitions in Anxiety and Motivation, eds R. Schwarzer (Hillsdale, NJ: Lawrence Erlbaum), 19-34.

Sarason, I. G. (1988). Anxiety, self-preoccupation and attention. Anxiety Res. 1, 3-7. doi: 10.1080/10615808808248215

Sashidharan, T., Pawlow, L. A., and Pettibone, J. C. (2012). An examination of racial bias in the beck depression inventory-II. Cultur. Divers. Ethnic Minor. Psychol. 18, 203-209. doi: 10.1037/a0027689
Schniering, C. A., and Rapee, R. M. (2004). The relationship between automatic thoughts and negative emotions in children and adolescents: a test of the cognitive content-specificity hypothesis. J. Abnorm. Psychol. 113, 464-470. doi: 10.1037/0021-843X.113.3.464

Segool, N. K., Carlson, J. S., Goforth, A. N., von der Embse, N., and Barterian, J. A. (2013). Heightened test anxiety among young children: elementary school students' anxious responses to high-stakes testing. Psychol. Sch. 50, 489-499. doi: 10.1002 /pits. 21689

Storch, E. A., Roberti, J. W., and Roth, D. A. (2004). Factor structure, concurrent validity, and internal consistency of the beck depression inventory-second edition in a sample of college students. Depress. Anxiety 19, 187-189. doi: 10.1002/da.20002

Sutton, J. M., Mineka, S., Zinbarg, R. E., Craske, M. G., Griffith, J. W., Rose, R. D., et al. (2011). The relationships of personality and cognitive styles with selfreported symptoms of depression and anxiety. Cognit. Ther. Res. 35, 381-393. doi: 10.1007/s10608-010-9336-9

Thomas, C. L., Cassady, J. C., and Heath, J. A. (2018). Examining the psychometric properties of the FRIEDBEN test anxiety scale using exploratory structural equation modeling. Int. J. Sch. Edu. Psychol. doi: 10.1080/21683603.2018.1522281. [Epub ahead of print].

Thomas, C. L., Cassady, J. C., and Heller, M. L. (2017). The influence of emotional intelligence, cognitive test anxiety, and coping strategies on undergraduate academic performance. Learn. Individ. Differ. 55, 40-48. doi: 10.1016/j.lindif.2017.03.001

Von der Embse, N., Jester, D., Roy, D., and Post, J. (2018). Test anxiety effects, predictors, and correlates: a 30-year meta-analytic review. J. Affect. Disord. 227, 483-493. doi: 10.1016/j.jad.2017.11.048

Von der Embse, N. P., Kilgus, S. P., Segool, N., and Putwain, D. (2013). Identification and validation of a brief test anxiety tool. Int. J. Edu. Sch. Psychol. 1, 246-258. doi: 10.1080/21683603.2013.826152

Vredenburg, K., O’Brien, E., and Krames, L. (1988). Depression in college students: personality and experiential factors. J. Couns. Psychol. 35, 419-425 doi: 10.1037/0022-0167.35.4.419

Watson, D., Clark, L. A., Weber, K., Assenheimer, J. S., Strauss, M. E., and McCormick, R. A. (1995). Testing a tripartite model: II exploring symptom structures of anxiety and depression in student, adult, and patient samples. J. Abnorm. Psychol. 104, 15-25. doi: 10.1037/0021-843X.104.1.15

Whisman, M. A., Perez, J. E., and Ramel, W. (2000). Factor structure of the beck depression inventory-second edition (BDI-II) in a student sample. J. Clin. Psychol. 56, 545-551. doi: 10.1002/(SICI)1097-4679(200004)56:4<545::AIDJCLP7>3.0.CO;2-U

Whisman, M. A., and Richardson, E. D. (2015). Normative data on the beck depression inventory - second edition (BDI-II) in college students. J. Clin. Psychol. 71, 898-907. doi: 10.1002/jclp.22188

Wittchen, H. U., Zhao, S., Kessler, R. C., and Eaton, W. W. (1994). DSMIII-R generalized anxiety disorder in the national comorbidity survey. Arch. Gen. Psychiatry 51, 355-364. doi: 10.1001/archpsyc.1994.039500500 15002

Yerkes, R. M., and Dodson, J. D. (1908). The relation of strength of stimulus to rapidity of habit forming. J. Compar. Neurol. Psychol. 18, 459-482.

Zeidner, M., and Matthews, G. (2005). "Evaluation anxiety: current theory and research," in Handbook of Competence and Motivation, eds A. J. Elliot and C. S. Dweck (New York, NY: Guilford Publications), 141-163.

Zunhammer, M., Eberle, H., Eichhammer, P., and Busch, V. (2013). Somatic symptoms evoked by exam stress in university students: the role of alexithymia, neuroticism, anxiety, and depression. PLoS ONE 8:e84911. doi: 10.1371/journal.pone.0084911

Conflict of Interest Statement: The authors declare that the research was conducted in the absence of any commercial or financial relationships that could be construed as a potential conflict of interest.

Copyright (c) 2019 Cassady, Pierson and Starling. This is an open-access article distributed under the terms of the Creative Commons Attribution License (CC BY). The use, distribution or reproduction in other forums is permitted, provided the original author(s) and the copyright owner(s) are credited and that the original publication in this journal is cited, in accordance with accepted academic practice. No use, distribution or reproduction is permitted which does not comply with these terms. 